\title{
How coping styles, cognitive distortions, and attachment predict problem gambling among adolescents and young adults
}

\author{
FILIPA CALADO $^{1 *}$, JOANA ALEXANDRE ${ }^{2}$ and MARK D. GRIFFITHS ${ }^{1}$ \\ ${ }^{1}$ International Gaming Research Unit, Psychology Department, Nottingham Trent University, Nottingham, United Kingdom \\ ${ }^{2}$ Department of Psychology, ISCTE - University Institute of Lisbon, Lisbon, Portugal
}

(Received: March 26, 2017; revised manuscript received: September 4, 2017; accepted: October 1, 2017)

\begin{abstract}
Background and aims: Recent research suggests that youth problem gambling is associated with several factors, but little is known how these factors might influence or interact each other in predicting this behavior. Consequently, this is the first study to examine the mediation effect of coping styles in the relationship between attachment to parental figures and problem gambling. Methods: A total of 988 adolescents and emerging adults were recruited to participate. The first set of analyses tested the adequacy of a model comprising biological, cognitive, and family variables in predicting youth problem gambling. The second set of analyses explored the relationship between family and individual variables in problem gambling behavior. Results: The results of the first set of analyses demonstrated that the individual factors of gender, cognitive distortions, and coping styles showed a significant predictive effect on youth problematic gambling, and the family factors of attachment and family structure did not reveal a significant influence on this behavior. The results of the second set of analyses demonstrated that the attachment dimension of angry distress exerted a more indirect influence on problematic gambling, through emotion-focused coping style. Discussion: This study revealed that some family variables can have a more indirect effect on youth gambling behavior and provided some insights in how some factors interact in predicting problem gambling. Conclusion: These findings suggest that youth gambling is a multifaceted phenomenon, and that the indirect effects of family variables are important in estimating the complex social forces that might influence adolescent decisions to gamble.
\end{abstract}

Keywords: adolescent gambling, attachment, cognitive distortions, coping styles, youth gambling

\section{INTRODUCTION}

Gambling is an activity that occurs in almost all cultures and across all age periods (Griffiths, 1995). However, the current generation of youth represents a vulnerable age group, given they have grown up in an era where gambling opportunities are widespread (Gupta \& Derevensky, 2000). While for most adolescents, gambling is an enjoyable and harmless activity, for a small minority, gambling can become problematic with severe negative consequences (Calado, Alexandre, \& Griffiths, 2017). Therefore, there is a need to study the risk factors underlying youth problem gambling to provide a more comprehensive description of this phenomenon and its onset. In addition, knowledge about risk factors is critical to identify the signs of youth problem gambling, which can be used to improve assessment tools and develop effective preventive initiatives.

Researchers have devoted substantial attention to adolescent gambling and its associated risk factors. Problem gambling is a multifaceted rather than unitary phenomenon (Griffiths, 2011), and consequently, many factors may come into play in various ways and at different levels that contribute to the acquisition, development, and maintenance of gambling-related problems. These factors can be conceptualized using an ecological model (Bronfrenbrenner \&
Morris, 1998), which addresses individual risk factors, as well as interpersonal and community factors that create the conditions for the development of youth gambling problems (Shead, Deverensky, \& Gupta, 2010).

At the individual level, most research has consistently found that gender is a risk factor for adolescent gambling problems. In fact, gambling is much more common among males than females (Kristiansen \& Jensen, 2014), and males are more vulnerable to develop gambling-related problems (Bastiani et al., 2013; Dodig, 2013; Olason et al., 2011).

In addition, at the individual level, some empirical research has examined cognitive distortions (e.g., Ariyabuddhiphongs, 2013; Griffiths, 1994; Tang \& Wu, 2012). According to some research, adolescent problem gamblers have erroneous beliefs about the independence of random gambling events and tend to overestimate their chances of winning (Delfabbro, Lahn, \& Grabosky, 2006; Froberg, 2006; Turner, Macdonald, Bartoshuk, \& Zangeneh, 2008).

\footnotetext{
* Corresponding author: Filipa Calado; International Gaming Research Unit, Psychology Department, Nottingham Trent University, 50 Shakespeare Street, Nottingham NG1 4FQ, United Kingdom; Phone: +44 115941 8418; E-mail: filipa.calado2013@ my.ntu.ac.uk
} 
Moreover, copying styles, which can be conceptualized as the way in which people deal with life circumstances, and regarded as a function of personality and experience (Shead et al., 2010), are also an important risk factor for the acquisition and maintenance of youth gambling problems. Such coping styles have been categorized into those intended to directly act on the stressor (i.e., task-oriented or problem-focused coping) and those intended to regulate emotional states associated with or resulting from stressful life events (i.e., emotion-oriented coping; Endler \& Parker, 1990; Folkman \& Lazarus, 1985). For instance, a study conducted by Gupta, Derevensky, and Marget (2004) reported that adolescents who gamble excessively exhibit coping styles that are more emotion-based. Bergevin, Gupta, Derevensky, and Kaufman (2006) also found that students aged between 11 and 20 years with gambling-related problems used less task-focused coping and more avoidancefocused coping strategies.

Some research also places importance on attitudes in predicting adolescents' gambling (e.g., Jackson, Dowling, Thomas, Bond, \& Patton, 2008; Moore \& Ohtsuka, 1999). In an Australian sample of 505 adolescents, Delfabbro and Thrupp (2003) found that more frequent gambling was associated with more pro-gambling attitudes. Similarly, a study carried out by Wood and Griffiths (2004) with 1,195 adolescents aged between 11 and 15 years showed that attitudes were an accurate predictor of adolescent gambling behavior when playing the National Lottery and scratch cards. Furthermore, a qualitative study conducted by Calado, Alexandre, and Griffiths (2014) demonstrated that adolescents displayed a positive attitude toward gambling behavior, and that gambling was associated with positive outcomes (e.g., more entertainment and a better life due to the money won).

It has also been shown that adolescent gambling behaviors are associated with numerous family characteristics, which can be conceptualized as family composition and parent-adolescent relationship characteristics (McComb \& Sabiston, 2010). In fact, previous research has found that a low-quality attachment to parents or other attachment figures have an influence in the initiation of other adolescent risky behaviors, such as drug use and delinquent behaviors (e.g., Kuntsche \& Kuendig, 2006; Miller, Jennings, Alvarez-Rivera, \& Lanza-Kaduce, 2009). Although not widely studied by gambling researchers, there was some preliminary evidence that attachment plays an important role in adolescent gambling behaviors (Magoon \& Ingersoll, 2006), which highlights the need for further research on this specific variable. This study examined the effect of attachment to parents or other attachment figures in youth problem gambling in an attempt to overcome the lack of attention to the influence of specific family variables in this behavior (McComb \& Sabiston, 2010).

In addition to attachment, some researchers have also noted that family composition, such as living with parents, might serve as a factor that might protect adolescents from engaging in this risky behavior (Hayer \& Griffiths, 2015). On the other hand, other empirical studies have reported that family configuration is not associated with adolescent gambling behavior (e.g., Langhinrichsen-Rohling, Rohde,
Seeley, \& Rohling, 2004). In fact, little empirical attention has been given to the relationship between family sociodemographic characteristics and adolescent gambling behaviors. This is despite the fact that they appear to be important variables in studying the context of gambling behavior because ecological models of health behavior recognize family demographic characteristics as determinants of health behavior (Flay \& Petraitis, 1994).

Although there is a growing body of literature on risk and protective factors, there is still a lack of consensus regarding the relative weight of each factor in contributing to problem gambling among youth (Shead et al., 2010). In fact, it is still unclear which variables (biological, cognitive, and family) play a more significant influence in the development of youth problematic gambling. Further research is needed to clarify the complex functional relationships between specific variables and to incorporate the individual and family predictors into a comprehensive and testable etiological model. Consequently, this study tested a model in which biological, cognitive, and family variables are integrated, weighting the contribution of each factor, and provided further insights into the mechanisms of these variables, by examining how these variables can interact and influence each other in the development of youth problematic gambling behavior.

Two sets of analysis were conducted. In the first set of analyses, the predictive power of a set of variables on gambling was examined (including gender along with cognitive, personality, and family factors), weighing the specific contribution of each predictor. This is in line with the conceptualization of gambling as a multifaceted (rather than unitary) phenomenon and therefore attempted to overcome previous research that mainly examined these predictors separately. In addition, this study overcomes the lack of research concerning family variables, namely the role of attachment to parents or other attachment figures in the emergence of youth gambling-related problems. It was hypothesized that biological, cognitive, and family variables would show different weights in predicting problem gambling among young people. The model hypothesized comprised the following. First, the starting model examined gender, and it was predicted that male gender would show a significant positive effect on youth problem gambling. Second, the individual predictors of cognitive distortions, attitudes, and coping were added to the model. It was predicted that these variables would show a significant predictive effect on youth problem gambling. Finally, the family variables of attachment and family structure were added to the model, and based on previous literature, it was predicted that attachment to parents would show a significant influence on youth problem gambling, whereas family structure would not have a significant predictive effect on this behavior. Based on this first set of analyses, a new model was hypothesized examining how individual and family variables influence each other in predicting youth problem gambling. The second set of analyses tested the hypothesized model, to provide further insights on the relationship between different types of variables that have a predictive role in the emergence of youth problem gambling. 


\section{METHOD}

\section{Participants and procedure}

The participants comprised 988 adolescents and young adults $(59.2 \%$ males, $40.8 \%$ females; mean age $=19.8$ years, $S D=2.0)$ attending high schools and the first year of college in the Nottinghamshire area of the UK. The data were collected using standard questionnaires, completed on a voluntary basis in the school or college.

\section{Measures}

Sociodemographic information and gambling frequency. Sociodemographic data were collected on age, gender, and family structure (participants had to indicate with whom they lived, i.e., if they lived with both birth parents, in a single-parent family, or with other family members). Participants were also asked to indicate how often they had gambled during the past year from 1 ("never") to 6 ("everyday").

DSM-IV-Multiple Response-Juvenile (DSM-IV-MR-J). The DSM-IV-MR-J is a psychometrically validated tool developed by Fisher (2000) for assessing adolescent problem gambling among those who have gambled during the past year. This instrument contains nine items, and assesses a number of important variables related to youth problem gambling, such as progression and preoccupation, tolerance, withdrawal, and loss of control. The response categories comprise $1=$ "never," 2 = "once or twice," $3=$ "sometimes," and 4 = "often." However, although each item has four response options, it receives a dichotomous scoring of 0 or 1 depending on the response choice (for instance, in the item 1 , if a person chooses the option "often," he/she will receive a score of 1 , but if he chooses any of the other options, he/she will receive a score of 0 ). Total score (range 0-9) was calculated by summing up the scores of all nine items. Participants who obtain a score of 0 or 1 are classified as social gamblers, a score of 2 or 3 indicates at-risk gambling, and a score of 4 or more indicates problem gambling. Cronbach's $\alpha$ for the instrument in this study was .82 .

Gambling-Related Cognitions Scale (GRCS). The 23-item GRCS was developed by Raylu and Oei (2004) to assess gambling-related erroneous cognitions. It comprises five subscales answered on a 7-point Likert scale, each one assessing a different type of cognitive distortion: gambling expectancies (i.e., expected benefits from gambling), illusion of control (i.e., the perceived ability to control gambling outcomes), predictive control (i.e., the misattribution of cause-effect relationships to unlinked events), inability to stop gambling (i.e., the perceived inability to stop gambling behavior), and interpretative bias (i.e., an error of assessment, such as attributing wins to personal abilities). Higher scores on the GRCS indicate higher levels of irrational belief. Cronbach's $\alpha$ for the instrument in this study was .94 .

Brief Coping Orientation to Problems Experienced (Brief COPE) Inventory. The "Brief COPE" developed by Carver (1997) is a short form of the original COPE inventory developed by Carver, Scheier, and Weintraub
(1989) and assesses different coping styles. This instrument comprises 14 subscales, each one measuring a different copying style: active coping, planning, positive reframing, acceptance, humor, religion, using emotional support, using instrumental support, self-distraction, denial, venting, substance use, behavioral disengagement, and self-blame. For this study [as used previously by Reinecke (2009)], the scores of the active coping and planning subscales were combined to form a single index for problem-focused coping, whereas the scores of the self-distraction and the denial subscales were combined to form an index of emotion-focused coping. The items of the problem-focused coping describe strategies that comprise problem-solving (e.g., "I concentrate my efforts on doing something about the situation I am in") and the items for the emotion-focused coping describe strategies that are directed to the regulation of emotions caused by the stressor (e.g., "I turn to work or other activities to turn my mind off things"). Participants were instructed to respond how often they reacted in the respective way when facing a problem on a Likert scale from 0 (never) to 3 (frequently). Cronbach's $\alpha$ s for the subscales in this study were .86 for the problem-focused subscale and .72 for the emotion-focused subscale.

Attitudes Towards Gambling Scale (ATGS). The ATGS8 is an instrument that was developed for the 2010 British Gambling Prevalence Survey by Wardle et al. (2011) to assess people's attitudes toward gambling. The scale comprises eight items with responses given on a 5-point Likert scale. Higher scores indicate more positive attitudes toward gambling. Cronbach's $\alpha$ for the instrument in this study was .75.

Adolescent Attachment Questionnaire (AAQ). The AAQ developed by West, Rose, Spreng, Sheldon-Keller, and Adam (1998) assesses adolescents' perceptions of relationship security with a nominated adult attachment figure on three continuous dimensions developed from Bowlby's specific ideas concerning the key characteristics of attachment relations. The first subscale (angry distress) comprises three items (e.g., "I get annoyed at my mum/dad, because it seems I have to demand his/her care and support") and assesses anger toward attachment figures when attachment needs are frustrated. The second subscale (availability) comprises three items (e.g., "I am confident that my mum/dad will listen to me") and is related to perceptions of the attachment figure as reliably responsive and available to the adolescent's attachment needs. The third subscale (goal-corrected partnership) also comprises three items (e.g., "I feel for my mum/dad when he/she is upset") and reflects Bowlby' concept that secure attachment bonds are characterized by an increasing sense of empathy toward the attachment figure. Individuals respond to these nine items on a 5-point Likert scale ranging from 1 (strongly disagree) to 5 (strongly agree). In this instrument, items of the availability and goal-corrected partnership subscales are reversed, so that higher scores on the total scale indicate lower levels of attachment. The total scale showed a Cronbach's $\alpha$ of .88 .

\section{First set of analyses}

Statistical analysis (1). For the first set of analyses, descriptive statistics were performed to report the gambling habits 
and gambling activities most played by participants. To identify the predictive factors for at-risk and problem gambling, a series of hierarchical logistic regressions were conducted using gender, cognitive distortions, attitudes, coping, attachment, and family structure as independent variables. In accordance with Potenza et al. (2011), the dependent variable in this logistic regression was the combination of at-risk and problem gambling, and was compared against non-problem gamblers (social and nonproblem gamblers).

\section{Ethics}

The study procedures were carried out in accordance with the Declaration of Helsinki. Parental permission to participate was provided for those students aged below 18 years and informed consent from all participants was obtained. Participants were requested not to write their names to maintain anonymity. Finally, the students were offered the possibility of contact with the authors in case they had questions or concerns regarding the study. The research team's university ethics committee provided approval for the study.

\section{RESULTS (PART 1)}

\section{Descriptive analysis of gambling habits and activities}

The results indicated that $79.4 \%$ of students had gambled during the past year. The most frequent gambling activities reported by participants were sports betting $(15.4 \%$ of respondents reported they gambled this activity often), scratch cards (14.7\%), and instant win games (10.7\%). When questioned about online gambling, the most frequent gambling activities were sports betting $(24.8 \%)$, gambling in social networking sites (7.2\%), and blackjack (5.7\%).

On the basis of the DSM-IV-MR-J criteria (Fisher, 2000 ), $20.4 \%$ of the participants were classified as nongamblers, $64.6 \%$ as social gamblers, $8.8 \%$ as at-risk gamblers, and $6.2 \%$ as problem gamblers.

\section{Model for predicting youth problematic gambling}

In the first regression analysis, the starting point was a model in which gender was the only predictor of the dependent variable (model 1; Table 1). This model classified $85.1 \%$ of respondents. In a second step, the cognitive distortions were added to the model (model 2). Comparing models 1 and 2 , the $\chi^{2}$ difference was significant, and justified the introduction of this variable. Model 2 correctly classified $86.9 \%$ of the respondents. In model 3, attitudes were added. Comparing models 2 and 3 , the $\chi^{2}$ difference was not significant. Finally, the remaining variables were individually added in subsequent steps to the model, and in each step, the $\chi^{2}$ significance was verified. The results indicated that the percentage of correctly classified respondents grew from 85.1 to 88.2 (Table 1). In the final model, the predictors were gender, cognitive distortions, attitudes, coping, attachment, and family structure (model 6).

The specific weight of each predictor is reported in Table 2. In addition, cognitive distortions showed a positive significant relationship with problematic gambling. Emotionfocused coping showed a significant positive relationship with problematic gambling, whereas problem-focused coping exhibited a negative significant relationship. Attitudes, attachment, and family structure did not show a significant relationship with problematic gambling.

\section{Second set of analyses}

The second set of analyses attempted to provide further insights in the relationship between the variables examined. The first set of analyses demonstrated that the individual factors of gender, cognitive distortions, and coping had a significant predictive effect on youth problematic gambling

Table 2. Logistic regression analysis with problematic gambling behavior (problem gambling/at-risk gambling) as the dependent variable $(N=988)$

\begin{tabular}{lcccccc}
\hline Predictors & $B$ & $S E$ & Wald & $d f$ & $p$ & OR \\
\hline Gender & -1.37 & 0.28 & 24.16 & 1 & $<.001$ & 0.26 \\
$\begin{array}{l}\text { Cognitive } \\
\quad \text { distortions }\end{array}$ & 1.18 & 0.13 & 89.1 & 1 & $<.001$ & 3.26 \\
$\quad$ & & & & & & \\
Attitudes & 0 & 0.02 & 0.00 & 1 & .986 & 1 \\
$\begin{array}{l}\text { Problem-focused } \\
\quad \text { coping }\end{array}$ & -0.12 & 0.04 & 7.645 & 1 & $<.01$ & 0.89 \\
$\quad$ Emotion-focused & 0.24 & 0.04 & 35.39 & 1 & $<.001$ & 1.27 \\
$\quad$ coping & & & & & & \\
$\begin{array}{l}\text { Attachment } \\
\text { Living with father }\end{array}$ & 0.05 & 0.16 & 0.09 & 1 & .764 & 1.05 \\
$\begin{array}{l}\text { Living with mother } \\
\text { Living with other }\end{array}$ & -0.58 & 0.47 & 0.17 & 1 & .69 & 1.21 \\
$\quad-0.32$ & 0.30 & 1.12 & 1 & .29 & 0.73 \\
$\quad$ family members & & & & & & \\
\hline
\end{tabular}

Table 1. Hierarchical logistic regression analysis with problematic gambling behavior (problem gambling/at-risk gambling) as the dependent variable $(N=988)$

\begin{tabular}{|c|c|c|c|c|c|}
\hline Model & $-2 \log$ & Correct classification $(\%)$ & Model comparison & $\Delta-2 \log$ & $p$ \\
\hline Model 1: Gender & 765.554 & 85.1 & & - & - \\
\hline Model 2: Model $1+$ cognitive distortions & 591.336 & 86.9 & Models 2-1 & 174.218 & $<.001$ \\
\hline Model 3: Model $2+$ attitudes & 590.808 & 86.9 & Models 3-2 & 0.528 & .468 \\
\hline Model 4: Model 3 + coping & 544.081 & 87.9 & Models 4-3 & 46.728 & $<.001$ \\
\hline Model 5: Model $4+$ attachment & 543.995 & 87.9 & Models 5-4 & 0.085 & .770 \\
\hline Model 6: Model 5 + household & 539.369 & 88.2 & Models 6-5 & 4.626 & .201 \\
\hline
\end{tabular}


(problem and at-risk gambling). The family predictors of attachment and family structure did not show a significant predictive effect on youth problematic gambling. These findings suggest that family variables do not have a direct impact in the emergence and maintenance of gambling behavior among young people, and contradict previous research on adolescent risky behaviors showing that a low level of attachment to parents or other attachment figures has a significant direct effect on adolescents' alcohol consumption (Kuntsche \& Kuendig, 2006), substance use (Bahr, Hoffman, \& Yang, 2005; Kopak, Chen, Haas, \& Gillmore, 2012), and deviant behavior (Miller et al., 2009).

In addition, lower levels of attachment have been associated with more avoidant coping strategies (Seiffge-Krenke \& Beyers, 2005), which showed a significant influence of problem gambling in the first set of analyses. In fact, some authors have argued that attachment theory should be an important base for understanding the origin of coping strategies (e.g., Howard \& Medway, 2004; Seiffge-Krenke, 2011). Adolescents securely attached to parents or to other attachment figures may develop a more positive selfimage in the long term, may be able to better manage stressful experiences, and develop more appropriate coping styles, such as problem-focused coping (Blomgren, Svahn, Åström, \& Rönnlund, 2016).

Consequently, the second set of analysis tested a model to see if coping strategies could mediate the relationship between attachment and gambling behavior and therefore advance knowledge on the influence of specific variables in youth problem gambling. To further understand how these variables can impact each other, the three attachment dimensions of angry distress, availability, and goal-corrected partnership, comprising the three subscales of the AAQ are considered. Therefore, based on the above analysis and previous literature showing a positive relationship between attachment and more healthy coping strategies, it was hypothesized that (i) attachment dimensions would not have a significant direct effect on youth problem gambling; (ii) the negative attachment dimension of angry distress would have a significant indirect effect on youth problem gambling, through emotion-focused coping style and problemfocused coping style; and (iii) the positive attachment dimensions of availability and goal-corrected partnership would have a significant indirect effect on youth problem gambling, through emotion-focused and problem-focused coping style.

Statistical analysis (2). In the second set of analyses, structural equation modeling (SEM) was used to assess the structural relationships between the predictor, mediator, and outcome variable. Considering that the outcome variable assessed by the DSM-IV-MR-J is a dichotomous variable, the WLSMV estimator implemented in Mplus was used (Muthén \& Muthén, 2015). The two-step approach to SEM recommended by Anderson and Gerbing (1988) was used by testing the measurement model in the first step and then the structural model in the second step. Conventional fit indices, independent of the sample size, were used to examine the goodness of fit of the model under analysis: root mean square error of approximation (RMSEA), the comparative fit index (CFI), and the Tucker-Lewis Index (TLI) (Vandenberg, 2006).

\section{RESULTS (PART 2)}

The means, standard deviations, and correlations between all the variables that will be included in the model are outlined in Table 3.

\section{SEM with latent constructs}

The criteria for acceptable model fit for these goodness-of-fit indices were defined by CFI $\geq 0.90$; TLI $\geq 0.90$; RMSEA $<$ 0.08 (Hu \& Bentler, 1999). Therefore, in the first step, the measurement model showed a very good model fit: $\mathrm{CFI}=0.968 ; \mathrm{TLI}=0.963 ; \mathrm{RMSEA}=0.031$.

In the second step, the structural model was tested. To examine mediation, bootstrapping procedures were conducted to determine the indirect effect (Preacher \& Hayes, 2008). The bootstrapping procedure has advantages over Baron and Kenny's (1986) traditional approach and Sobel's (1982) test, because it does not assume normality of the sampling distribution of the indirect effects, and it has higher power while maintaining adequate control over type I error rate (MacKinnon, Lockwood, Hoffman, West, \& Shets, 2002; Preacher \& Hayes, 2008). The bootstrap estimates were based on 1,000 bootstrap samples. An indirect effect was considered to be significant if its $95 \%$ bias-corrected and accelerated (BCa) bootstrap CIs from 1,000 bootstrap samples exclude zero (Fritz, Taylor, \& MacKinnon, 2012). The full structural model again showed a very good model fit: $\mathrm{CFI}=0.969 ; \mathrm{TLI}=0.965$; RMSEA $=0.030$.

The direct path from attachment dimensions to problem gambling was non-significant. As mentioned above, the attachment dimensions of availability and goal-corrected partnership were reversed, so higher scores on these

Table 3. Correlations between all the attachment dimensions, copying styles, and problem gambling

\begin{tabular}{|c|c|c|c|c|c|c|c|c|}
\hline & $M$ & $S D$ & 1 & 2 & 3 & 4 & 5 & 6 \\
\hline 1. Angry distress & 1.90 & 0.93 & & $0.526^{* *}$ & $0.385^{* *}$ & $-0.091 * *$ & $0.205 * *$ & 0.057 \\
\hline 2. Availability & 2.10 & 0.92 & $0 . \overline{52} 6^{* *}$ & - & $0.616^{* *}$ & $-0.205^{* *}$ & $0.093 * *$ & 0.025 \\
\hline 3. Goal-corrected partnership & 1.81 & 0.75 & $0.385^{* *}$ & $0.616^{* *}$ & - & $-0.244 * *$ & -0.006 & 0.041 \\
\hline 4. Problem-focused coping & 7.44 & 2.92 & $-0.091 * *$ & $-0.205^{* *}$ & $-0 . \overline{24} 4 * *$ & - & 0.049 & $-0.149 * *$ \\
\hline 5. Emotion-focused coping & 4.34 & 2.86 & $0.205^{* *}$ & $0.093^{* *}$ & -0.006 & 0.049 & - & $0.202 * *$ \\
\hline 6. Problem gambling & 0.72 & 1.55 & 0.057 & 0.025 & 0.041 & $-0.149 * *$ & $0.202 * *$ & - \\
\hline
\end{tabular}

**Correlation is significant at the $p<.01$ level. 
dimensions reveal low levels of availability and goalcorrected partnership, respectively. The direct path from emotion-focused coping to problem gambling was positively significant and the direct path from problem-focused coping was negatively significant (Table 4). Therefore, the first hypothesis was fully supported.

In addition, results relating to the second hypothesis indicated that the total effect from the attachment dimension of angry distress to problem gambling was significant $(B=0.35 ; S E=0.12 ; p<.05)$. The results also showed that the total indirect effect was also significant $(B=0.12 ; 95 \%$ $\mathrm{BCa} \mathrm{CI}=0.03,0.19$ ). Examining the indirect effect, the results indicated that the specific indirect effect from angry distress to problem gambling through emotion-focused coping was significant $(B=0.13 ; 95 \% \mathrm{BCa} C I=0.06$, $0.20)$. However, as noted in Table 4 , the direct effect from angry distress to problem gambling was not significant
$(B=0.24 ; S E=0.15 ; p=.11)$. Therefore, these results indicate that emotion-focused coping fully mediated the relationship between angry distress and problem gambling. Moreover, the results indicate that the specific indirect effect from angry distress to problem gambling via problemfocused coping was not significant $(B=-0.01 ; 95 \% \mathrm{BCa}$ $\mathrm{CI}=-0.06,0.02)$. Consequently, the second hypothesis was partially confirmed (see Figure 1 for the significant indirect path from angry distress to problem gambling).

The results for the third hypothesis indicated that the total effect from availability to problem gambling was not significant $(B=-0.197 ; S E=0.19 ; p=.31)$. The total indirect effect was not significant either $(B=0.03 ; 95 \% \mathrm{BCa}$ $\mathrm{CI}=-0.05,0.16)$. With regard to the attachment dimension of goal-corrected partnership, the total effect from this dimension to problem gambling was non-significant $(B=0.07$; $S E=0.14 ; p=.60)$. In addition, the total indirect effect from

Table 4. Direct paths to all dependent variables in the study (unstandardized regression coefficients)

\begin{tabular}{lrrr}
\hline & $B$ & $S E$ & $p$ \\
\hline Direct paths to problem gambling & & & \\
Angry distress $\longrightarrow$ problem gambling & 0.24 & 0.15 & .11 \\
Availability $\longrightarrow$ problem gambling & -0.22 & 0.27 & .41 \\
Goal-corrected partnership $\longrightarrow$ problem gambling & 0.11 & 0.199 & .58 \\
Emotion-focused coping $\longrightarrow$ problem gambling & $\mathbf{0 . 9 2}$ & $\mathbf{0 . 2 4}$ & $<.001$ \\
Problem-focused coping $\longrightarrow$ gambling & $\mathbf{- 0 . 2 3}$ & $\mathbf{0 . 0 6}$ & $<.001$ \\
Direct paths to emotion-focused coping & & & \\
Angry distress $\longrightarrow$ emotion-focused coping & $\mathbf{0 . 1 4}$ & $\mathbf{0 . 0 6}$ & $\mathbf{. 0 2 3}$ \\
Availability $\longrightarrow$ emotion-focused coping & -0.00 & 0.08 & .97 \\
Goal-corrected partnership $\longrightarrow$ emotion-focused coping & -0.07 & 0.05 & .20 \\
Direct paths to problem-focused coping & & & \\
Angry distress $\longrightarrow$ problem-focused coping & 0.05 & 0.11 & .62 \\
Availability $\longrightarrow$ problem-focused coping & -0.12 & 0.24 & .62 \\
Goal-corrected partnership $\longrightarrow$ problem-focused coping & -0.12 & 0.20 & .56 \\
\hline
\end{tabular}

Note. The values represented in bold are statistically significant.

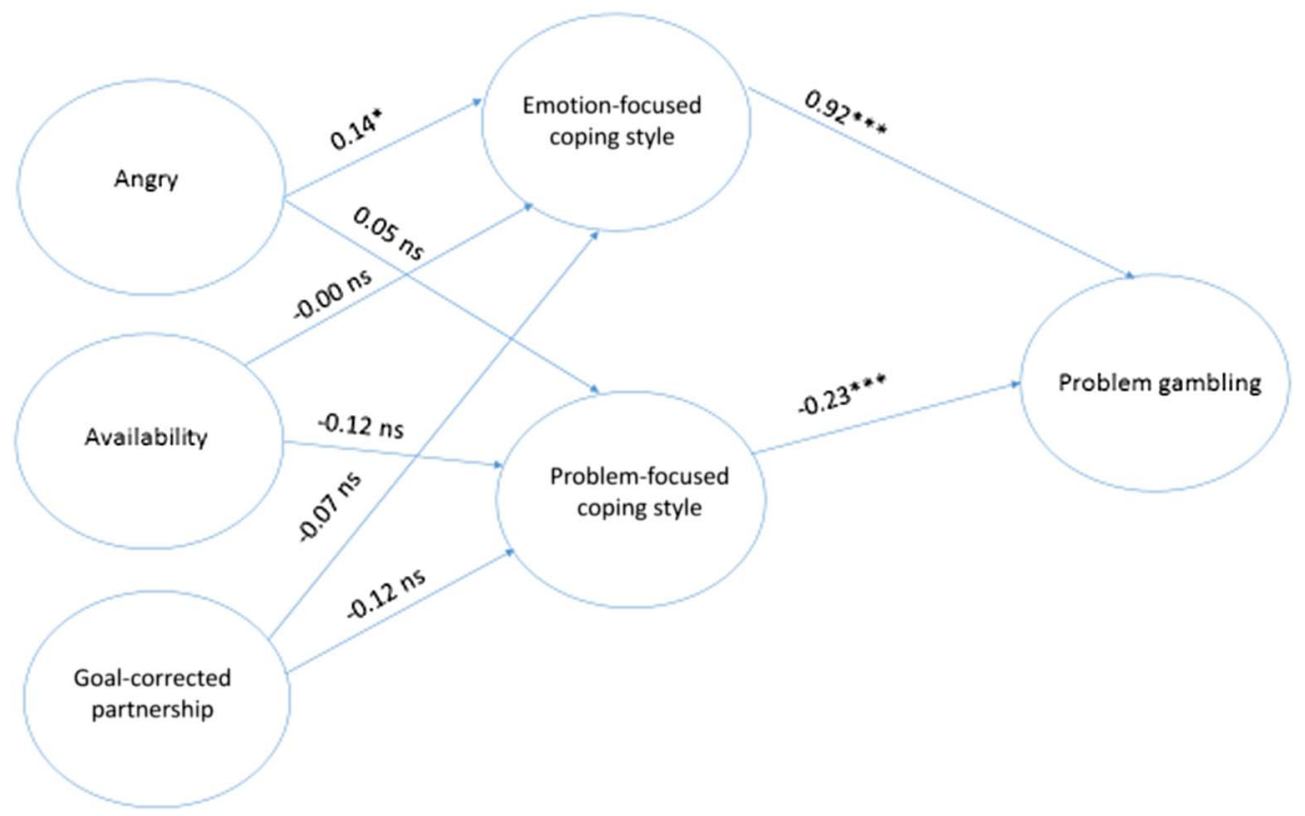

Figure 1. Indirect effects from the three attachment dimensions to problem gambling. ns: non-significant. ${ }^{*} p>.05$. ${ }^{* * *} p>.001$ 
goal-corrected partnership to problem gambling, via the two coping styles was not significant either $(B=-0.04 ; 95 \% \mathrm{BCa}$ $\mathrm{CI}=-0.14,0.04)$. Therefore, these results suggest that there is no mediation of coping styles in the relationship between the attachment dimensions of angry distress and goalcorrected partnership and problem gambling. This model accounted for a total of $22 \%$ of the variance in problem gambling, $14.6 \%$ of the variance in emotion-focused coping, and $4.3 \%$ in the variance of problem-focused coping.

\section{DISCUSSION}

This study explored the effect of individual and family predictors upon problem gambling, and examined the relationship between some individual and family variables in the prediction of problem gambling among a student sample. The first set of analyses showed that a model composed of individual and family factors together adequately explained youth problematic gambling. The second set of analyses demonstrated that attachment dimensions do not have a significant direct effect on problem gambling among young people, and that the attachment dimension of angry distress exerted a significant indirect influence on youth problem gambling.

The findings of the first set of analyses are in line with other research (e.g., Griffiths, 2011), which asserts that gambling is a multidimensional (rather than a unitary) phenomenon and therefore many factors may come into play in the acquisition, development, and maintenance of gambling-related problems. Within this integrated perspective, the most significant variables for predicting youth problem gambling were male gender, cognitive distortions, and emotion-focused coping. These findings are also in line with previous research showing that problematic gambling behavior is more prevalent among males (e.g., Bastiani et al., 2013; Griffiths, 2011, Skokauskas \& Satkeviciute, 2007), associated with erroneous beliefs of randomness (e.g., Delfabbro et al., 2006; Griffiths, 1994) and with emotion-focused coping (e.g., Bergevin et al., 2006). However, in this study, attitudes did not show a significant effect on youth problematic gambling, contradicting previous research highlighting the impact of this variable in predicting gambling-related problems among young people. Therefore, more research into the effect of attitudes on youth gambling is needed among diverse samples, to understand the meaning of gambling-related attitudes in different cultural contexts and its influence in the emergence of this behavior.

The first set of analyses also showed that the family predictors of attachment to parents or other attachment figures, and family structure did not show a significant effect on youth problem gambling. These findings confirm other studies showing that family structure does not have a significant impact on youth problem gambling (e.g., Langhinrichsen-Rohling et al., 2004) but contradicts other studies showing that attachment has a significant effect on other adolescent risky behaviors (e.g., Bahr et al., 2005). Consequently, these findings suggest that attachment to parents or other attachment figures may have an indirect effect on youth problematic gambling via other individual variables. As previous research has demonstrated that attachment has an influence on coping strategies (Seiffge-Krenke \& Beyers, 2005), and that a primary function of interpersonal attachment is the regulation of emotions (McNally, Palfai, Levine, \& Moore, 2003), the second set of analyses examined if coping styles mediated the relationship between attachment to parents and problem gambling.

To better understand the complex relationships between these variables, the second set of analyses examined the three dimensions of attachment (angry distress, availability, and goal-corrected partnership). The findings indicated that none of these dimensions had a significant direct effect on problem gambling. However, the attachment dimension of angry distress exerted a significant indirect effect on problem gambling via emotion-focused coping, and which fully mediated the relationship between angry distress and problem gambling. Problem-focused coping did not exert any mediation in the relationship between angry distress and problem gambling. In addition, the other attachment dimensions of availability and goal-corrected partnership did not exert any significant indirect effect on youth problem gambling via any coping style. Therefore, these results suggest that the attachment dimension of angry distress, characterized by feelings of anger toward attachment figures when attachment needs are frustrated (West et al., 1998), has a major effect in the emergence of emotion-focused coping, characterized by strategies of regulating emotions caused by the stressor. This, in turn, will exert an influence in the development of gambling-related problems among young people.

Although there was some preliminary evidence that attachment plays a role in adolescent gambling behaviors (Magoon \& Ingersoll, 2006), these findings extend the previous gambling literature by examining how different attachment dimensions can exert an effect on youth problem gambling via coping styles, and by showing that the attachment dimension of angry distress indirectly influenced this behavior via an emotion-focused coping style.

The findings of this study have some important implications for clinical practice and prevention. In fact, it seems that a low-quality relationship with parents or other attachment figures may lead youngsters to learn less suitable strategies to deal with their life difficulties, such as using gambling to escape from their problems (Wood \& Griffiths, 2007). Therefore, in a clinical context with young problem gamblers, therapists should assess the quality of the parentchild relationship, namely potential feelings of anger that adolescents might feel toward their parents when their needs are unfulfilled, and must include parents or other attachment figures in the therapeutic process. In addition, during preventive initiatives, parents should also be trained about their abilities and aptitudes that could foster the development of a positive relationship with their children.

Although this study has some strengths, such as a relatively large sample size and the examination of previously unexplored relationships between attachment dimensions, coping styles, and problem gambling, it has also some limitations. These should be kept in mind when interpreting the findings. Most importantly, this study exclusively 
utilized self-report data, which are prone to various wellknown biases, such as social desirability and memory recall biases. Second, the study was conducted among a student sample recruited in England and therefore generalizability to other populations is limited. Third, this study used a crosssectional design, and thus possible causal relationships between variables cannot be inferred.

Despite these limitations, this is the first study, as far as the authors are aware, to examine the mediation effect of coping styles in the relationship between attachment and problem gambling. This confirms that the indirect effects of family variables are important in estimating the complex social forces that may influence adolescent decisions to gamble. However, future studies should be conducted in other countries in different contexts and with a wider range in age to extend the present findings to other youth populations. Moreover, there is a need for replication of these results in longitudinal designs. Considering that youth problem gambling has several negative consequences, longitudinal studies as well as investigations carried out in other contexts could be of great utility in minimizing these outcomes.

Funding sources: FC received a grant from FCT, Portuguese national funding agency for science, research and technology (reference number SFRH/BD/119749/2016). MDG has received funding for a number of research projects in the area of gambling education for young people, social responsibility in gambling, and gambling treatment from the Responsibility in Gambling Trust, a charitable body, which funds its research program based on donations from the gambling industry. He also undertakes consultancy for various gaming companies in the area of social responsibility in gambling.

Authors' contribution: FC and MDG designed the study. FC collected and analyzed the data. All authors inputted into the interpretation of the results. FC wrote the initial draft of the paper and MDG added significantly to the first draft. All authors then went through a number of iterative versions before the final manuscript was submitted. All authors have full access to all the data in the study and take responsibility for the integrity of the data and the accuracy of the data analysis.

Conflict of interest: FC and JA declare no conflict of interest.

Acknowledgements: The authors would like to thank Tadeusz Borejko for his assistance in participant recruitment and data collection.

\section{REFERENCES}

Anderson, J. C., \& Gerbing, D. W. (1988). Structural equation modeling in practice: A review and recommended two-step approach. Psychological Bulletin, 103(3), 411-423. doi:10. 1037/0033-2909.103.3.411
Ariyabuddhiphongs, V. (2013). Adolescent gambling: A narrative review of behavior and its predictors. International Journal of Mental Health and Addiction, 11(1), 97-109. doi:10.1007/ s11469-012-9401-6

Bahr, S., Hoffman, J., \& Yang, X. (2005). Parental and peer influences on the risk of adolescent drug use. Journal of Primary Prevention, 26(6), 529-551. doi:10.1007/s10935005-0014-8

Baron, R., \& Kenny, D. (1986). The moderator-mediator variable distinction in social psychological research: Conceptual, strategic, and statistical considerations. Journal of Personality and Social Psychology, 51(6), 1173-1182. doi:10.1037/00223514.51.6.1173

Bastiani, L., Gori, M., Colasante, E., Siciliano, V., Capitanucci, D., Jarre, P., \& Molinaro, S. (2013). Complex factors and behaviours in the gambling population of Italy. Journal of Gambling Studies, 29(1), 1-13. doi:10.1007/s10899-011-9283-8

Bergevin, T., Gupta, R., Derevensky, J., \& Kaufman, F. (2006). Adolescent gambling: Understanding the role of stress and coping. Journal of Gambling Studies, 22(2), 195-208. doi:10. 1007/s10899-006-9010-z

Blomgren, A. S., Svahn, K., Åström, E., \& Rönnlund, M. (2016). Coping strategies in late adolescence: Relationships to parental attachment and time perspective. Journal of Genetic Psychology, 177(3), 85-96. doi:10.1080/00221325.2016.1178101

Bronfrenbrenner, U., \& Morris, P. A. (1998). The ecology of developmental processes. In Lerner, R. (Ed.), Handbook of child psychology: Theoretical models of human development (5th ed., Vol. 1, pp. 993-1028). New York, NY: John Wiley.

Calado, F., Alexandre, J., \& Griffiths, M. D. (2014). Mom, Dad it's only a game! Perceived gambling and gaming behaviors among adolescents and young adults: An exploratory study. International Journal of Mental Health and Addiction, 12(6), 772-794. doi:10.1007/s11469-014-9509-y

Calado, F., Alexandre, J., \& Griffiths, M. D. (2017). Prevalence of adolescent problem gambling: A systematic review of recent research. Journal of Gambling Studies, 33(2), 397-424. doi:10. 1007/s10899-016-9627-5

Carver, C. S. (1997). You want to measure coping but your protocol's too long: Consider the brief COPE. International Journal of Behavioral Medicine, 4(1), 92-100. doi:10.1207/ s15327558ijbm0401_6

Carver, C. S., Scheier, M. F., \& Weintraub, J. K. (1989). Assessing coping strategies: A theoretically based approach. Journal of Personality and Social Psychology, 56(2), 267-283. doi:10.1037/0022-3514.56.2.267

Delfabbro, P., Lahn, J., \& Grabosky, P. (2006). It's not what you know, but how you use it: Statistical knowledge and adolescent problem gambling. Journal of Gambling Studies, 22(2), 179 193. doi:10.1007/s10899-006-9009-5

Delfabbro, P., \& Thrupp, L. (2003). The social determinants of youth gambling in South Australian adolescents. Journal of Adolescence, 26(3), 313-330. doi:10.1016/S0140-1971(03) 00013-7

Dodig, D. (2013). Assessment challenges and determinants of adolescents' adverse psychosocial consequences of gambling. Kriminologija i Socijalna Integracija, 21, 1-29.

Endler, N. S., \& Parker, J. D. A. (1990). Coping Inventory for Stressful Situations (CISS): Manual. Toronto, Canada: MultiHealth Systems. 
Fisher, S. (2000). Developing the DSM-IV-MR-J criteria to identify adolescent problem gambling in nonclinical populations. Journal of Gambling Studies, 16(2-3), 253-273. doi:10.1023/ A:1009437115789

Flay, B. R., \& Petraitis, J. (1994). The theory of triadic influence: A new theory of health behavior with implications for preventive interventions. Advances in Medical Sociology, 4, 19-44.

Folkman, S., \& Lazarus, R. A. (1985). If it changes it must be a process: A study of emotion and coping during three stages of a college examination. Journal of Personality and Social Psychology, 48(1), 150-170. doi:10.1037/00223514.48.1.150

Fritz, M. S., Taylor, A. B., \& MacKinnon, D. P. (2012). Explanation of two anomalous results in statistical mediation analysis. Multivariate Behavioral Research, 47(1), 61-87. doi:10.1080/ 00273171.2012 .640596

Froberg, F. (2006). Gambling among young people. A knowledge review. Stockholm, Sweden: Swedish National Institute of Public Health.

Griffiths, M. D. (1994). The role of cognitive bias and skill in fruit machine gambling. British Journal of Psychology, 85(3), 351369. doi:10.1111/j.2044-8295.1994.tb02529.x

Griffiths, M. D. (1995). Adolescent gambling. London, UK: Routledge.

Griffiths, M. D. (2011). Adolescent gambling. In Bradford Brown, B. \& Prinstein, M. J. (Eds.), Encyclopedia of adolescence (Vol. 3, pp. 11-20). San Diego, CA: Academic Press.

Gupta, R., Derevensky, J., \& Marget, N. (2004). Coping strategies employed by adolescents with gambling problems. Child and Adolescent Mental Health, 9(3), 115-120. doi:10.1111/j.14753588.2004.00092.x

Gupta, R., \& Derevensky, J. L. (2000). Adolescents with gambling problems: From research to treatment. Journal of Gambling Studies, 16(2-3), 315-342. doi:10.1023/A:1009493200768

Hayer, T., \& Griffiths, M. D. (2015). The prevention and treatment of problem gambling in adolescence. In Gullotta, T. P. \& Adams, G. (Eds.), Handbook of adolescent behavioural problems: Evidence-based approaches to prevention and treatment (2nd ed., pp. 539-558). New York, NY: Springer.

Howard, M. S., \& Medway, F. J. (2004). Adolescents' attachment and coping with stress. Psychology in the Schools, 41(3), 391402. doi:10.1002/pits.10167

Hu, L., \& Bentler, P. M. (1999). Cutoff criteria in fix indexes in covariance structure analysis: Conventional criteria versus new alternatives. Structural Equation Modeling, 6(1), 1-55. doi:10. 1080/10705519909540118

Jackson, A. C., Dowling, N., Thomas, S. A., Bond, L., \& Patton, G. (2008). Adolescent gambling behaviour and attitudes: A prevalence study and correlates in an Australian population. International Journal of Mental Health and Addiction, 6(3), 325-352. doi:10.1007/s11469-008-9149-1

Kopak, A. M., Chen, A. C. C., Haas, S. A., \& Gillmore, M. R. (2012). The importance of family factors to protect against substance use related problems among Mexican heritage and White youth. Drug and Alcohol Dependence, 124(1-2), 34-41. doi:10.1016/j.drugalcdep.2011.12.004

Kristiansen, S. G., \& Jensen, S. M. (2014). Prevalence and correlates of problematic gambling among Danish adolescents. International Journal of Social Welfare, 23(1), 89-99. doi:10.1111/ijsw.12021
Kuntsche, E. N., \& Kuendig, H. (2006). What is worse? A hierarchy of family-related risk factors predicting alcohol use in adolescence. Substance Use and Misuse, 41(1), 71-86. doi:10.1080/10826080500368694

Langhinrichsen-Rohling, J., Rohde, P., Seeley, J. R., \& Rohling, M. L. (2004). Individual, family and peer correlates of adolescent gambling. Journal of Gambling Studies, 20(1), 23-46. doi:10.1023/B:JOGS.0000016702.69068.53

MacKinnon, D. P., Lockwood, C. M., Hoffman, J. M., West, S. G., \& Sheets, V. (2002). A comparison of methods to test mediation and other intervening variable effects. Psychological Methods, 7(1), 83-104. doi:10.1037/1082-989X.7.1.83

Magoon, M. E., \& Ingersoll, G. M. (2006). Parental modeling, attachment, and supervision as moderators of adolescent gambling. Journal of Gambling Studies, 22(1), 1-22. doi:10.1007/ s10899-005-9000-6

McComb, J. L., \& Sabiston, C. M. (2010). Family influences on adolescent gambling behavior: A review of the literature. Journal of Gambling Studies, 26(4), 503-520. doi:10.1007/ s10899-010-9181-5

McNally, A. M., Palfai, T. P., Levine, R. V., \& Moore, B. M. (2003). Attachment dimensions and drinking-related problems among young adults. The mediational role of coping motives. Addictive Behaviors, 28(6), 1115-1127. doi:10.1016/S03064603(02)00224-1

Miller, H. V., Jennings, W. G., Alvarez-Rivera, L. L., \& LanzaKaduce, L. (2009). Self-control, attachment, and deviance among Hispanic adolescents. Journal of Criminal Justice, 37(1), 77-84. doi:10.1016/j.jcrimjus.2008.12.003

Moore, S. M., \& Ohtsuka, K. (1999). Beliefs about control over gambling among young people, and their relation to problem gambling. Psychology of Addictive Behaviors, 13(4), 339-347. doi:10.1037/0893-164X.13.4.339

Muthén, L. K., \& Muthén, B. O. (2015). Mplus user's guide (7th ed.). Los Angeles, CA: Muthén \& Muthén.

Olason, D. T., Kristjansdottir, E., Einarsdottir, H., Haraldsson, H., Bjarnason, G., \& Derevensky, J. L. (2011). Internet gambling and problem gambling among 13 to 18 year old adolescents in Iceland. International Journal of Mental Health and Addiction, 9(3), 257-263. doi:10.1007/s11469-010-9280-7

Potenza, M. N., Wareham, J. D., Steinberg, M. A., Rugle, L., Cavallo, D. A., Krishnan-Sarin, S., \& Desai, R. A. (2011). Correlates of at-risk/problem internet gambling in adolescents. Journal of American Academy of Child and Adolescent Psychiatry, 50(2), 150-159.e3. doi:10.1016/j.jaac.2010.11.006

Preacher, K., \& Hayes, A. (2008). Asymptotic and resampling strategies for assessing and comparing indirect effects in multiple mediator models. Behavior Research Methods, 40(3), 879-891. doi:10.3758/BRM.40.3.879

Raylu, N., \& Oei, T. P. (2004). The Gambling Related Cognitions Scale (GRCS): Development, confirmatory factor validation and psychometric properties. Addiction, 99(6), 757-769. doi:10.1111/j.1360-0443.2004.00753.x

Reinecke, L. (2009). Games and recovery: The use of video and computer games to recuperate from stress and strain. Journal of Media Psychology, 21(3), 126-142. doi:10.1027/1864-1105. 21.3.126

Seiffge-Krenke, I. (2011). Coping with relationship stressors: A decade review. Journal of Research on Adolescence, 21(1), 196-210. doi:10.1111/j.1532-7795.2010.00723.x 
Seiffge-Krenke, I., \& Beyers, W. (2005). Coping trajectories from adolescence to young adulthood: Links to attachment state of mind. Journal of Research on Adolescence, 15(4), 561-582. doi:10.1111/j.1532-7795.2005.00111.x

Shead, N. W., Derevensky, J. L., \& Gupta, R. (2010). Risk and protective factors associated with youth problem gambling. International Journal of Adolescent Medicine and Health, 22, 39-58.

Skokauskas, N., \& Satkeviciute, R. (2007). Adolescent pathological gambling in Kaunas, Lithuania. Nordic Journal of Psychiatry, 61(2), 86-91. doi:10.1080/08039480701226054

Sobel, M. (1982). Asymptotic confidence intervals for indirect effects in structural equation models. Sociological Methodology, 13, 347-355. doi:10.2307/270723

Tang, C. S.-K., \& Wu, A. M. S. (2012). Gambling-related cognitive biases and pathological gambling among youths, young adults, and mature adults, in Chinese societies. Journal of Gambling Studies, 28(1), 139-154. doi:10.1007/s10899-011-9249-x

Turner, N. E., Macdonald, J., Bartoshuk, M., \& Zangeneh, M. (2008). Adolescent gambling behaviour, attitudes, and gambling problems. International Journal of Mental Health and Addiction, 6(2), 223-237. doi:10.1007/s11469-007-9117-1
Vandenberg, R. J. (2006). Statistical and methodological myths and urban legends: Where, pray tell, did they get this idea? Organizational Research Methods, 9(2), 194-201. doi:10. 1177/1094428105285506

Wardle, H., Moody, A., Spence, S., Orford, J., Volberg, R., Jotangia, D., Griffiths, M., Hussey, D., \& Dobbie, F. (2011). The British gambling prevalence survey 2010. London, UK: The Stationery Office.

West, W., Rose, S. M., Spreng, S., Sheldon-Keller, A., \& Adam, K. (1998). Adolescent attachment questionnaire: A brief assessment of attachment in adolescence. Journal of Youth and Adolescence, 27(5), 661-673. doi:10.1023/A:102289 1225542

Wood, R. T., \& Griffiths, M. D. (2004). Adolescent lottery and scratchcard players: Do their attitudes influence their gambling behaviour? Journal of Adolescence, 27(4), 467-475. doi:10. 1016/j.adolescence.2003.12.003

Wood, R. T., \& Griffiths, M. D. (2007). A qualitative investigation of problem gambling as an escape-based coping strategy. Psychology and Psychotherapy: Theory, Research and Practice, 80(1), 107-125. doi:10.1348/147608306X107881 